\title{
Car Exhaust Waste Heat Recovery using Hexagon Shaped Thermoelectric Generator
}

Muhammad Fairuz Remeli*, Baljit Singh, Aiman Ismail

Energy Conservation for Automotive Research Group, School of Mechanical, College of Engineering, Universiti Teknologi MARA, Shah

Alam, 40450 Selangor, Malaysia.

*corresponding author: fairuz1299@uitm.edu.my

\section{ABSTRACT}

Heat recovery technology using thermoelectric has attracted many research intentions mainly for its ability to generate power passively. The automotive engine usually produces waste heat ranging from $30-40 \%$ due to the thermodynamic limit. The use of thermoelectric generator (TEG) for waste heat recovery and power generation could increase the efficiency of internal combustion engine system. The objective of the research was to determine a suitable location for TEG placement at the car exhaust and to test a hexagonal TEG generator performance for electricity generation. The thermoelectric generator (TEG) consisted of two thermoelectric cells (TECs), a hexagonal pipe connector, and heat sinks which were connected to an exhaust pipeline. The TEC cells were connected in series and parallel circuits. Testing was conducted to measure the OCV and the TECs' temperature gradient. The maximum power output, maximum current, voltage, and maximum efficiency were predicted based on the temperature difference between the TEC temperature gradients. The series-connected TECs were found to have higher OCV compared to the parallel connection with $0.13 \mathrm{~V}$ for a small temperature gradient of $3^{\circ} \mathrm{C}$. The series-connected TECs were capable to produce $0.12 \mathrm{~mW}$ electric power with $0.09 \%$ efficiency. Hopefully in the future, this system could replace the car alternator for charging the battery as well as increasing the overall efficiency of the engine system.

Keywords: Thermoelectric generator, heat recovery, exhaust gas, waste heat, Seebeck effect

\section{Nomenclature (Greek symbols towards the end)}

$\begin{array}{ll}U & \text { Voltage }(\mathrm{V}) \\ \alpha & \text { Seebeck coefficient }(\mathrm{V} / \mathrm{K}) \\ T_{c} & \text { the temperature of the TEC cold side }\left({ }^{\circ} \mathrm{C}\right) \\ T_{h} & \text { the temperature of the TEC hot side }\left({ }^{\circ} \mathrm{C}\right)\end{array}$

\section{Abbreviations}

$\begin{array}{ll}\text { TEG } & \text { Thermoelectric generator } \\ \text { ICE } & \text { Internal combustion engine }\end{array}$

\subsection{INTRODUCTION}

The limitation of an internal combustion engine (ICE) is that only $30 \%$ of the fuel combustion is converted into mechanical energy. The $70 \%$ remaining energy is wasted through a lubricant engine cooling and exhaust system [1-3]. An exhaust heat recovery system is needed to extract the waste heat and converting it into electricity. Most of the current engine heat recovery system involves an active system that requires rotating part including a small turbine in an organic Rankine cycle and turbocharger technology. These types of systems are expensive and not maintenance-free. Another promising technology to replace this system is thermoelectric. Thermoelectric technology is a passive heat transfer device (non-moving) that can directly convert the wasted thermal energy into electricity without using any moving parts [4-5].

A thermoelectric generator (TEG) is a device that can directly convert heat into electricity. It is a solid device and has no moving parts [7]. The TEG operates based on the Seebeck effect [8] when two dissimilar conductors are connected and two junctions are maintained at hot and cold temperatures, while an electromotive force or potential difference (voltage) is developed between this junction. Fig. 1 shows the concept of electricity generation using thermoelectricity [9]. It is known that thermal energy can free an electron from an atomic bond of a conductor material even at normal temperature. However, when a temperature gradient is applied across a conductor as shown in Fig. 1, more free electrons are produced on the hot side. The electrons (charge carriers 
including holes) will naturally diffuse from the hot side to the cold side. An electromotive force (voltage) is created when an electric current runs in the opposite direction of the temperature difference [6].

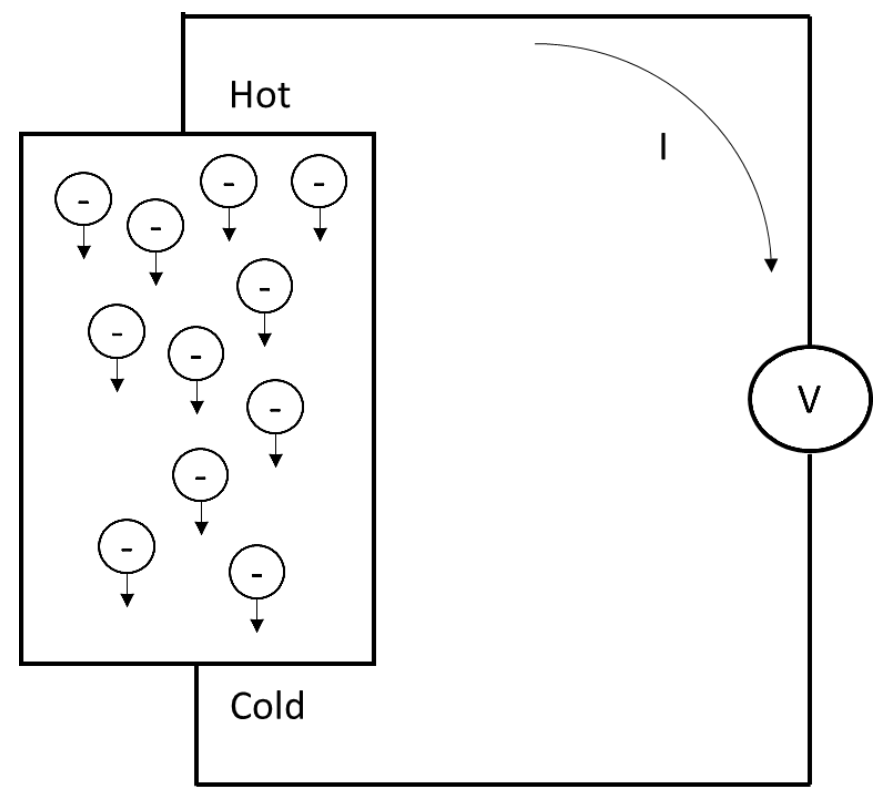

Figure1. The concept of a thermoelectric generator to produce electricity

The electric voltage is proportional to the temperature difference across the hot surface and cold surface of the TEG as given by [6]:

$$
U=\alpha\left(T_{h}-T_{c}\right)
$$

Where $U$ is the open-circuit voltage, $\alpha$ is called the Seebeck coefficient (also called thermopower), $T_{h}-T_{c}$ is the temperature difference between the hot and the cold side of TEG.

Some researchers have converted the vehicle thermal waste into electricity using the TEG technology [10-11]. İlker Temizer and Cumali İlkılıç [12] designed a prototype of thermoelectric generator (TEG) system that is powered by a diesel engine. The performance of TEG was examined by changing the engine speed and engine load. Changxin Liu et al. [13] proposed a novel prototype two-stage thermoelectric generator (TEG) from a vehicle's exhaust. This system could generate power of about $250 \mathrm{~W}$ at $473 \mathrm{~K}$ hot side temperature with a thermal efficiency of $5.35 \%$.

Yang et al. [14] developed a system for heating a bus cabin by recovering exhaust gas heat using a heat pipe heat exchanger (HPHE). The heated air was directed back to the cabin for space heating. Hsiao et al. [15] presented a theoretical model of thermoelectric generator (TEG) for the use in an automotive application. An exhaust pipe and a radiator in the automotive were identified as possible locations for applying this system. The theoretical model was developed using a one-dimensional thermal resistance method. It was found that the TEG performed better on the exhaust pipe than on the radiator. Tzeng et al. [16] tested a TEG system including replicating an exhaust system. The metal pin fins were used as a heat absorber and heat sink in this system. They developed 1D steady heat conduction model which included the Joule heat generation and the Seebeck effect. The model agreed well with the experimental data which confirmed its validity.

Kim et al. [17] investigated thermoelectric power generation by using the hot exhaust gas from a hybrid vehicle. The limited space near a hot exhaust pipe was extended by using 10 sections of heat pipes. Moreover, the excess heat from the exhaust gas was transferred efficiently to the hot surface of the TEG using these heat pipes. The other surface of the TEG was cooled by water. The system produced approximately $350 \mathrm{~W}$ of electricity at an evaporator surface temperature of $170^{\circ} \mathrm{C}$.

Goncalves et al. [18] utilized a variable conductance heat pipe (VCHP) to control high-temperature exhaust gas from an engine and to suit the TEG operating temperature. The system was predicted to generate approximately $550 \mathrm{~W}$ of electric power for an engine input power of $30 \mathrm{~kW}$. Kim et al. [11] developed a lowtemperature TEG system using heat from an engine water coolant. They claimed that the system could potentially substitute the conventional radiator without adding other mechanical devices. This system generated around 75 $\mathrm{W}$ of electric power which was equivalent to around $2.1 \%$ TEG conversion efficiency. 
This study was conducted to determine a suitable location and to design a system to harness the exhaust gas heat for electricity generation using a thermoelectric generator (TEG). The TEG used in this study has a limited temperature range. Exceeding the maximum TEG temperature value might damage the device since its soldering material will melt. The material selection for the system component becomes a crucial factor since it needs to be a good conductor and able to reduce high gas temperature to the maximum operating range of the selected TEG. The exhaust gas temperature may vary along its pipeline and it is important to determine a suitable location to place the TEG. The closer the TEG is placed at the engine exit, the higher is the temperature. For this experiment, the commercial bismuth telluride (Bi2Te3) TEGs were used as the measured exhaust temperature in a static condition of around $200^{\circ} \mathrm{C}$. The bismuth telluride TEG is known for its low-grade temperature range applications. The available waste heat energy can be converted to power using the thermoelectric generator. By only having a small temperature gradient across the TEG material, it can produce usable voltage for minor car electronics equipment and air conditioner as well as reduce the shaft power that consumes the alternator [19].

Based on the above discussion, it is really important to find a suitable location to place the TEG on the exhaust pipe where it can withstand the heat without damaging its soldering material. Fig. 2 shows the temperature distributions in the BMW $318 \mathrm{i} 1995 \mathrm{~cm}^{3}$ exhaust system, which is powered by a $96 \mathrm{~kW}$ gasoline engine. The engine could operate at both half and full load. The Melcor HT9-3-25 TEGs were tested in this study. The maximum power and efficiency were analysed at different points of the exhaust pipe after the catalyst used hot temperature data, particularly at partial load [20]. The temperature profile demonstrated a pattern of decreasing temperature from the section near the engine outlet to the rear muffler. According to the graph, the TEG system should be put anywhere between the catalyst and rear muffler where the hot temperature drop ranged from $300^{\circ} \mathrm{C}$ to $200^{\circ} \mathrm{C}$.

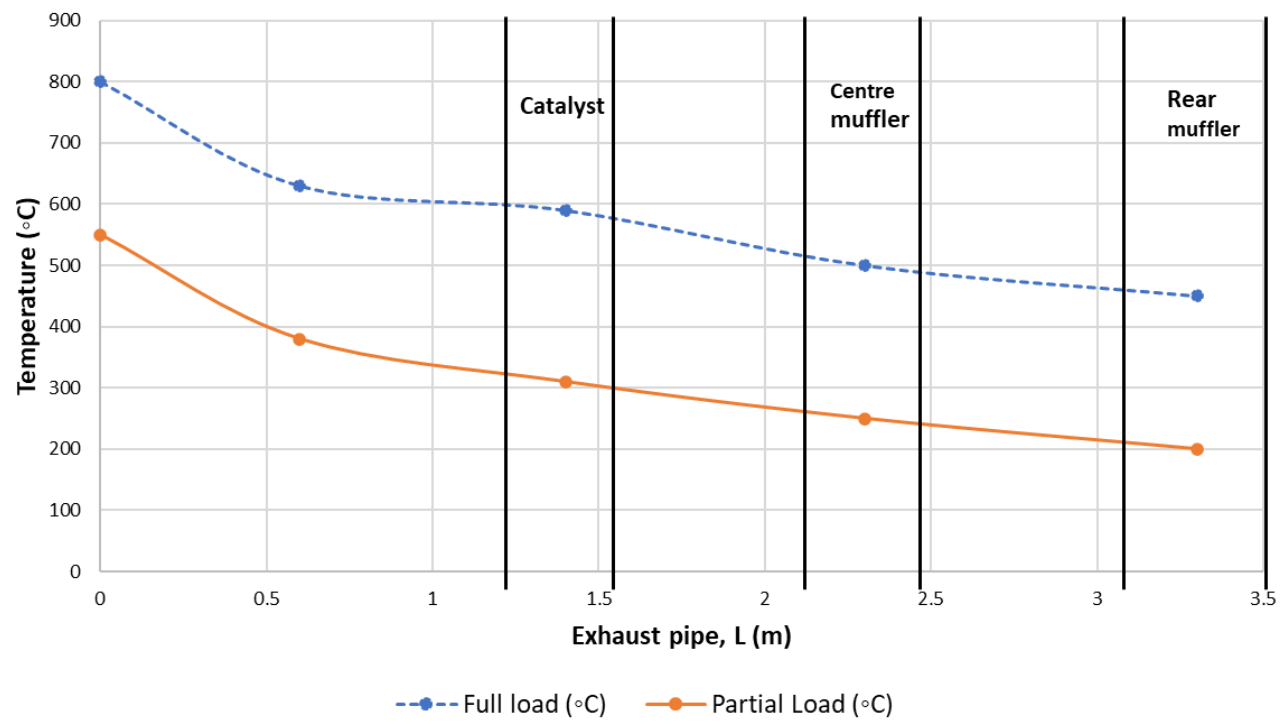

Figure 2. Temperature distribution of exhaust pipeline

The fuel consumption can be reduced up to $5 \%$ with the current technology since the TEG can always be improved to achieve better temperature difference as the TEG technology will only advance with a new combination of material that is able to withstand higher temperature and able to convert the temperature difference to a better voltage reading in the future [20]. Big companies such as BMW, General Motors (GM) and Volkswagen has begun to develop a highly efficient TEG for the recovery heat system [21]. However, there are compatible issues where the pressure drop will affect the engine exhaust system directly [22].

Many prior investigations have focused on power generation from automobile exhaust. However, there are still some details in the design of this TEG system that need to be improved. The first is that, because most systems use square-shaped commercial TEGs, installing TEGs to the surface of a round-shaped exhaust pipe is rather challenging. In addition, most TEGs have a maximum operating temperature restriction. As a result, it is vital to determine the ideal location for the TEC on the exhaust section that does not exceed the melting temperature. As a result, the goal of this research is to determine the best exhaust section for TEG installation as well as to design and test a hexagon-shaped TEG system. 


\subsection{METHODOLOGY}

The TEG setup was fabricated using several processes. The material used was a standard aluminium 6000 series. Aluminium was selected as it is often used for a manifold that can withstand great temperature; it is cheap, easily acquire, and also lightweight. However, there are several types of aluminium ore. The one that was chosen for this project was the aluminium block with a solid cylindrical shape, where the shape of the product would be more solid and have better heat distribution.
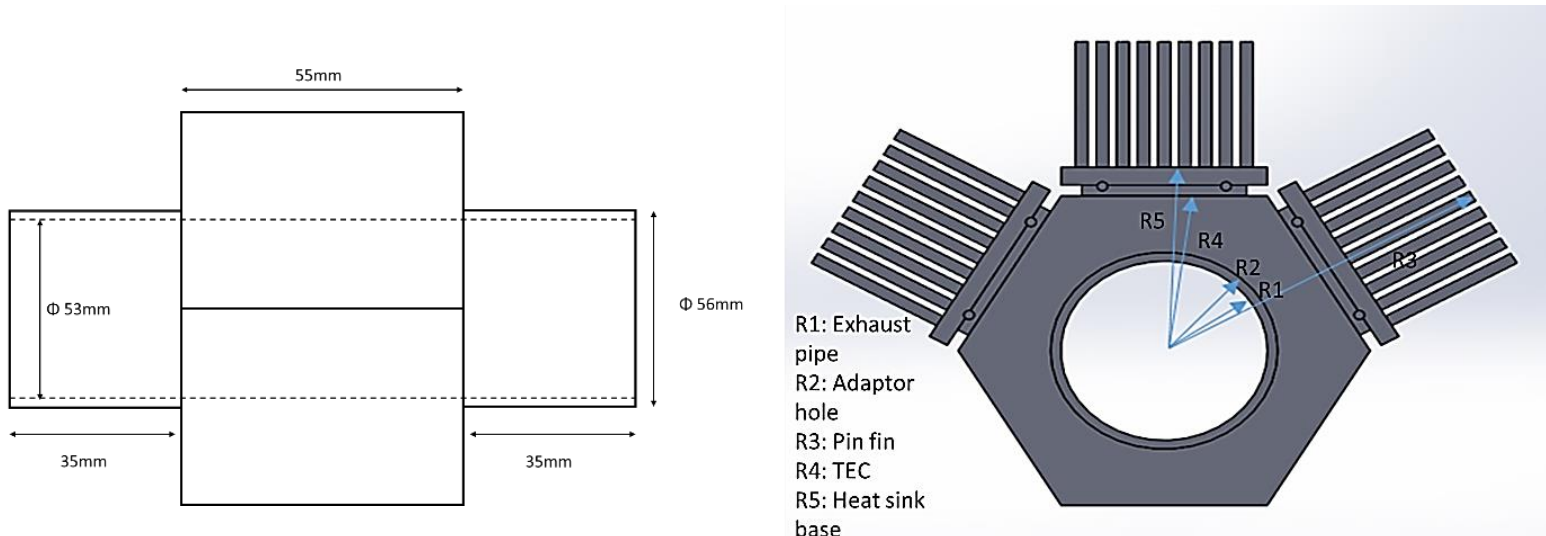

Figure 3. The hexagonal-TEG exhaust adaptor dimension

Fig. 3 shows that the aluminium block was drilled with $53 \mathrm{~mm}$ diameter to fit the adaptor into the exhaust pipe. The outer part of the block was milled to form hexagon-shaped. A hexagon shape was chosen to ease the placement of the TEC and the heat sink. This hexagon design was fabricated to increase the surface area as the number of TEC that can be placed on the hexagon was up to six (6) TECs compared to a rectangular shape that can place only up to four (4) TECs. The TEC and heat sink were attached to the adaptor by using a mechanism as shown in Fig. 4. This connecting mechanism was to ensure a secured connection between the adaptor, TEC and heat sink. The thermal paste was also applied between the TEC interface to enhance the heat conduction process.

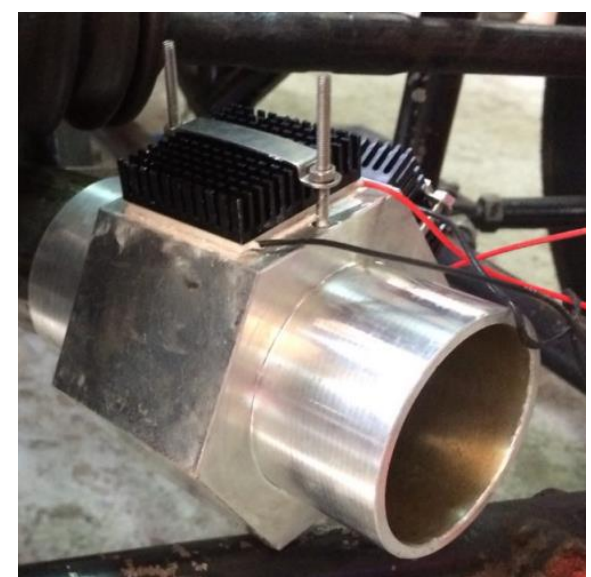

Figure 4. The TEG exhaust testing unit 


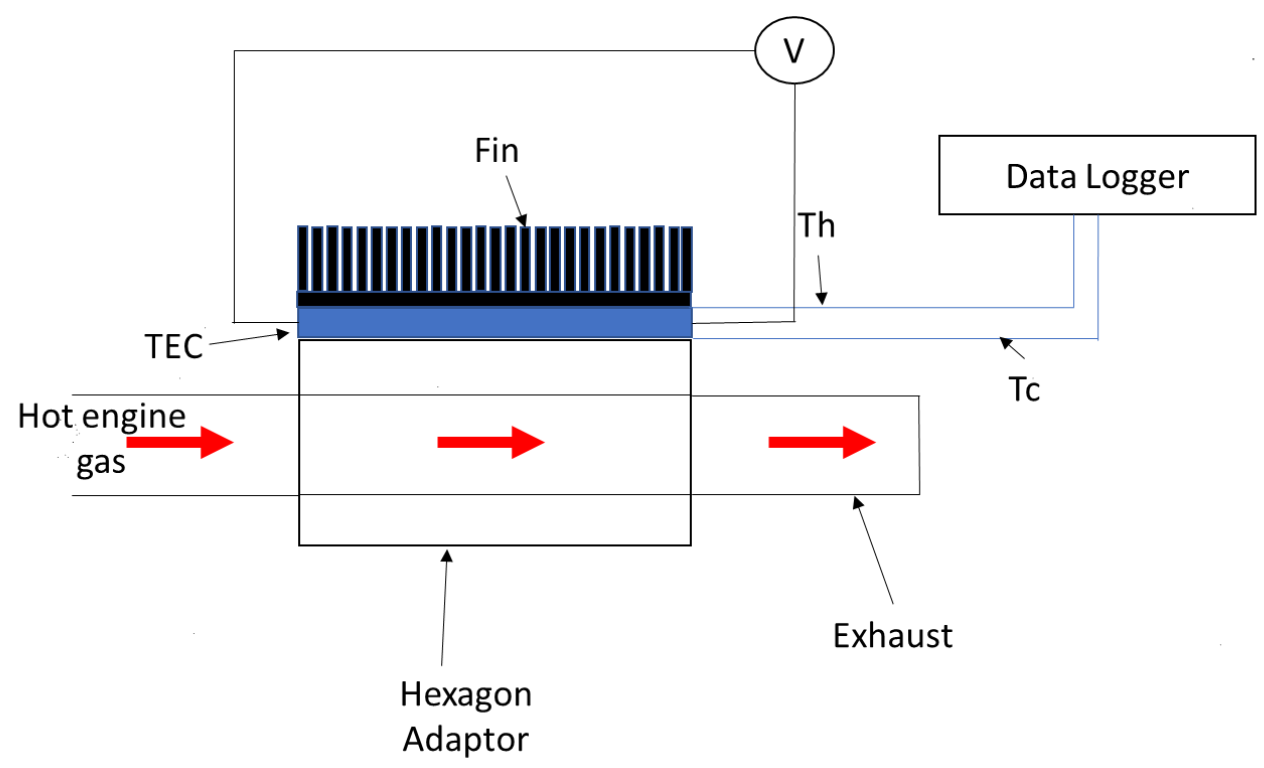

Figure 5. Schematic of the experimental set-up
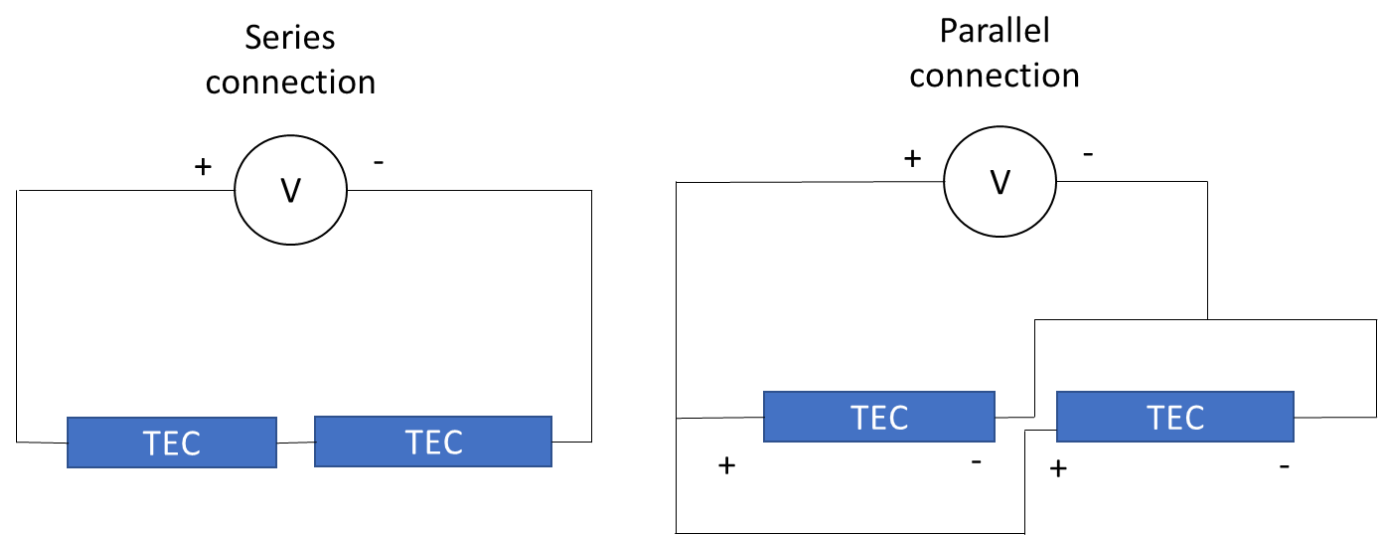

Figure 6. Series and parallel connection of the TEG

As shown in Fig. 5, the experiment started by fitting the hexagonal TEG generator into the exhaust pipe. The car engine was started and warmed-up for 30-40 minutes in an idle condition. A set of thermocouples were connected to a data logger for monitoring and measuring the temperature data. Once a steady-state condition was achieved, the temperatures of the hot side and cold side of the TEC surfaces were recorded. The open-circuit voltage $(\mathrm{OCV})$ was also measured by using a multimeter. In this testing, only two thermoelectric cells (TECs) were attached to the hexagonal adaptor. The first testing was conducted by connecting the TECs in series as shown in Fig. 6. Then it was proceeded by the parallel connection. The temperature and OCV data were recorded every 5 minutes after the steady-state condition.

\subsection{RESULTS AND DISCUSSION}

The BITARA racing car engine was used for the testing. The engine was maintained at $2000 \mathrm{rpm}$ during the testing. Fig. 7 shows the open-circuit voltage (OCV) of the series and the parallel connection of the TEG (refer to Fig. 6). It clearly shows that the OCV for series connection was higher than the parallel connection. This is because in a series connection, the voltage created is combined, resulting in a greater voltage reading as the number of TEGs increases. On the other hand, for the parallel connection, the OCV was lower since the generated voltage was evenly distributed for each TEC. However, for this testing set-up, the maximum number of TEC that can be used was 6. Only 2 TECs were installed for this testing due to a few constraints. The highest recorded OCV was $0.132 \mathrm{~V}$ for series connection at $3^{\circ} \mathrm{C}$ temperature difference between the hot and cold side of TEC, $\Delta \mathrm{T}$. Meanwhile, the highest generated $\mathrm{OCV}$ for parallel was $0.073 \mathrm{~V}$ at $2.83^{\circ} \mathrm{C}$ of $\Delta \mathrm{T}$. 


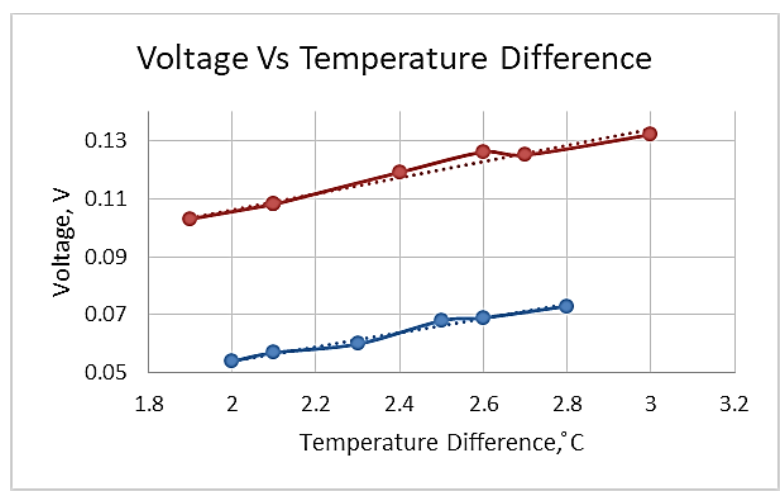

Figure 7. Graph of Experimental Open Circuit Voltage (OCV) versus TEC temperature difference (Series (red), Parallel (blue)).

The maximum output power could not be measured during the experiment since the current value was so small and unreadable by the multimeter. Therefore, the electrical power output and the maximum efficiency of the TEG were estimated using the equations as follow:

Maximum power output, $\mathrm{W}_{\mathrm{mp}}$ occurs when the external load, $\mathrm{R}_{\mathrm{L}}=\mathrm{R}_{\mathrm{e}}$ (internal resistance) :

$$
W_{m p}=I_{m p}{ }^{2} R_{L}
$$

where the maximum current output, $\mathrm{I}_{\mathrm{mp}}$ :

$$
I_{m p}=\frac{\alpha\left(T_{h}-T_{C}\right)}{2 R_{e}}
$$

where $\mathrm{R}_{\mathrm{e}}$ is the internal resistance of the TEC :

$$
R_{e}=\frac{\rho L_{e}}{A_{e}}
$$

The electrical resistivity is $\rho=1.64 \mathrm{e}-3 \Omega \mathrm{cm}$ for both junctions and the thermal conductivity is $0.0146 \mathrm{~W} / \mathrm{cm}^{\circ} \mathrm{C}$. The length of the thermoelectric element, $L_{e}=1.0 \mathrm{~cm}$, and its cross-sectional area, $A_{e}=1.2 \mathrm{~cm}^{2}$. The output voltage across the load, $\mathrm{V}_{\mathrm{L}}$ at the maximum power is calculated by:

$$
V_{L}=I_{m p} R_{L}
$$

The conversion efficiency of the maximum power is obtained by:

$$
\mu_{m p}=\frac{W_{m p}}{Q_{m p}}
$$

Where the $\mathrm{Q}_{\mathrm{mp}}$ is the heat absorbed at the hot junction:

$$
Q_{m p}=\alpha T_{h} I_{m p}-\frac{1}{2} I_{m p}{ }^{2} R_{e}+K_{e} A_{e} \frac{T_{h}-T_{c}}{L_{e}}
$$

Fig. 8 compares the maximum power output against the temperature difference, $\Delta T$. Both series and parallel connections showed a similar trend in which the power output rose with an increase of temperature difference. The series connection produced a maximum power of $0.12 \mathrm{~mW}$, while the parallel produced $0.02 \mathrm{~mW}$ lesser. This was due to the lower current and voltage produced by the parallel connection as shown in Fig. 9.

The maximum power production was plotted versus the temperature differential, $\Delta \mathrm{T}$, as in Fig. 8 . Both the series and parallel connections exhibited a similar pattern in which the power output increased as the temperature difference increased. The series connection produced a maximum power of $0.12 \mathrm{~mW}$, while the parallel produced $0.02 \mathrm{~mW}$ lesser. This was because the parallel connection produced less current as seen in Fig. 9.

If the TECs are connected in series and exposed to a non-uniform temperature gradient, the output voltage for each TECs will reduce. Although each output voltage of the TECs is not the same, overall, the total voltage of the 
series connection is higher because they are summed together. Also, the series connection is able to produce more power because of the reduction of Joule heating losses in wiring due to lower current output [23].

Ideally, the parallel connection array has lower voltage and higher current that results in higher Joule heating or $I^{2} \mathrm{R}$ losses in the wiring system and the resistance network [24]. Also, under non-uniform temperature gradient between each TEC unit, it causes a mismatch in current magnitude that contributes to lower power output.

Fig. 10 shows the maximum efficiency produced by both connection systems. It was quite clear that the series connection produced higher efficiency with the peak value of $0.09 \%$, while the parallel connection was slightly lower with $0.08 \%$. In the future, circuit connections should use smarter systems such as the maximum power point tracking (MPPT) where it can optimize power output regardless whether the connection is in series, parallel, and hybrid.

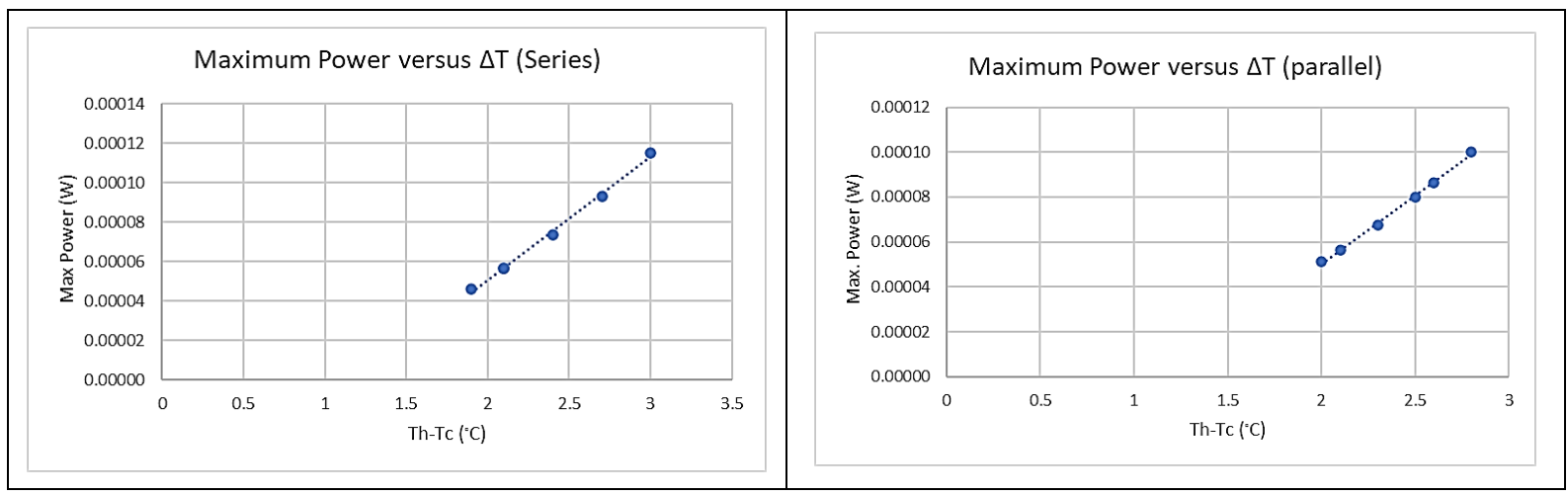

Figure 8. Graph of the maximum power versus TEC temperature difference

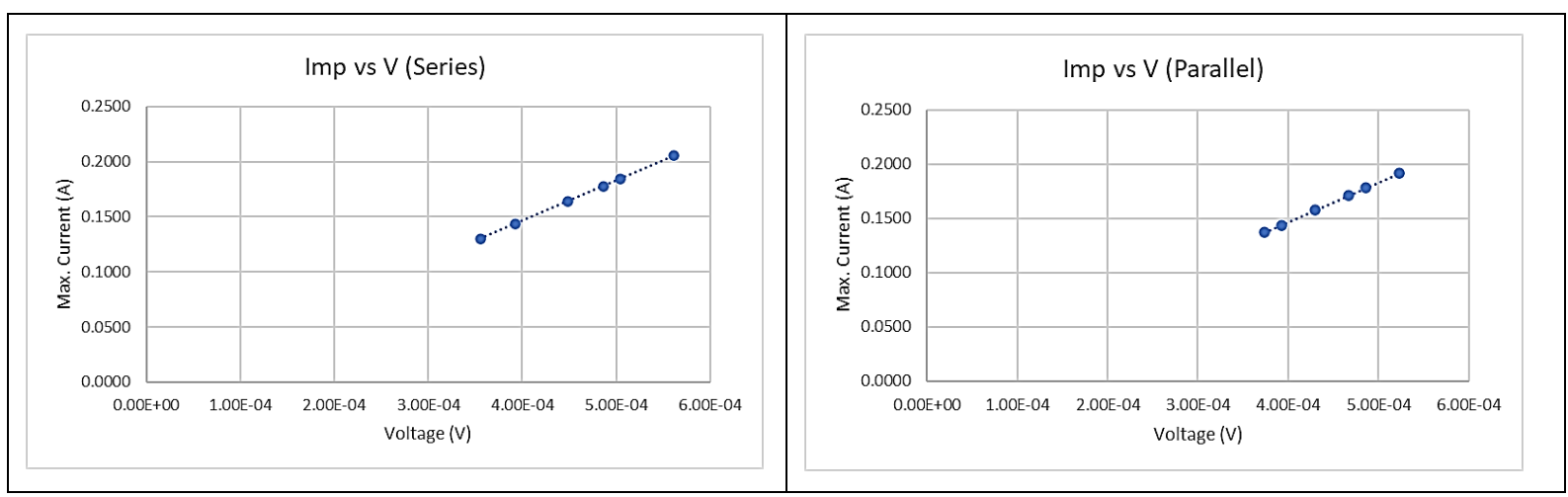

Figure 9. Graph of maximum current versus voltage

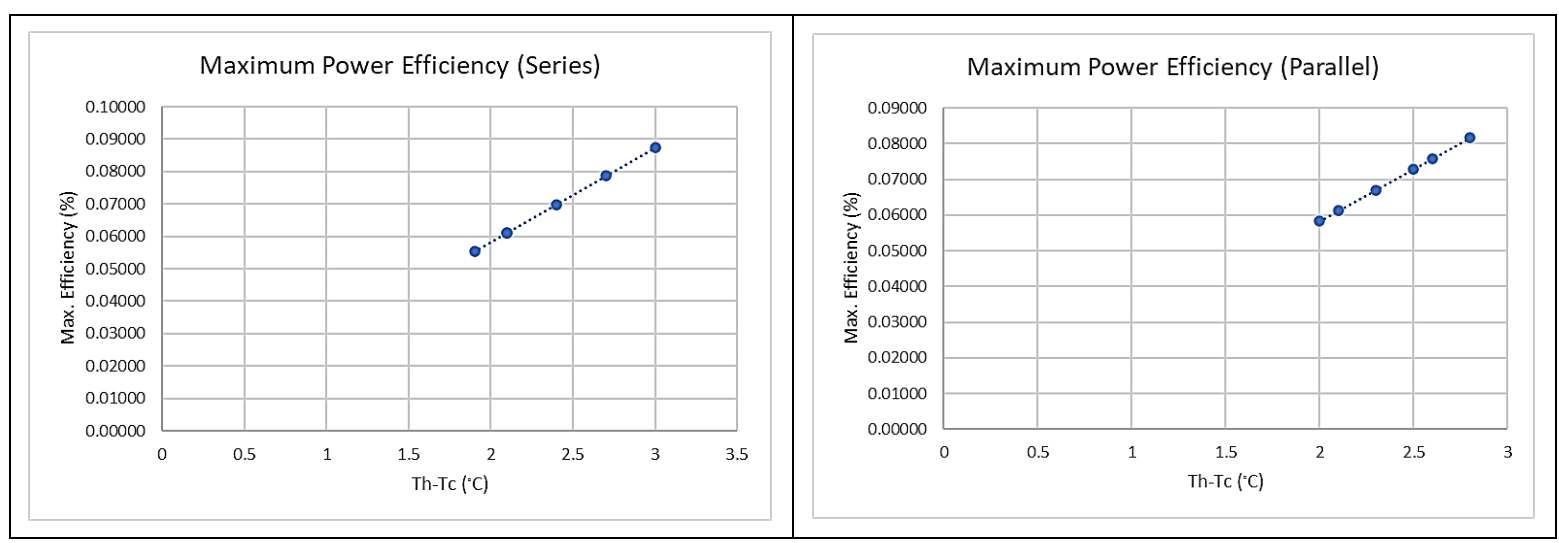

Figure 10. Graph of the maximum power efficiency versus TEC temperature difference 


\subsection{CONCLUSION}

This study presents a unique hexagonal-shaped TEG generator that is connected to an exhaust pipe of a car engine. The generator is able to accommodate a maximum of 6 pieces of TEC on the hexagonal adaptor of the exhaust pipe. This design is important in easing the interconnection between the hot exhaust pipe that has a round shape with the flat surface of the commercial TEG. The testing also investigates the performance of the series and parallel electrical wiring of the TEG. It is found that the series connection performance is superior compared to the parallel one especially when the heat distribution is not uniformly distributed across the TEC surfaces. The testing of the TEG system produces only a small temperature difference between the hot and cold TEC surfaces. This contributes to a small power output of $0.12 \mathrm{~mW}$ with $0.09 \%$ of maximum electrical efficiency conversion. It is found that the low voltage produced in this experiment is due to the poor fabrication of the heat sink. The hexagon plate (on the hot side of the TEG) is made from stainless steel with low thermal conductivity. It is also machined too thick that prevents infective heat conduction from the hot gas to the TEG. This problem might contribute to the low voltage produced in this experiment. Due to the uncertain behaviour of the vehicle, the rpm of the vehicle has an unsteady idling time. The reading could not be taken for any longer than 45 minutes as the engine starts to heat up so high. The coolant system of the exhaust is also at fault since the coolant has little to no value in reducing the heat of the engine. The hot heat emitted from the engine also affects the ambient temperature as well, reducing the efficiency of the heat sink to dissipate the heat to the atmosphere. In conclusion, the TEG will have better efficiency if the exhaust has a steady heat distribution by reducing the fault of unstable idling time of the engine which can cause high heat emission to the surrounding and lead to an inefficient heat sink.

\section{ACKNOWLEDGEMENT}

The financial grant scheme from LESTARI (grant no: 600-RMC/MyRA 5/3/LESTARI (057/2020)) Universiti Teknologi MARA (UiTM) is gratefully acknowledged.

\section{REFERENCES}

[1] M. F. Remeli, B. Singh, N. D. N. Affandi, L. C. Ding, A. Date, and A. Akbarzadeh, "Investigation of Counter-Flow in a Heat Pipe-Thermoelectric Generator (HPTEG)," J. Electron. Mater., vol. 46, no. 5, pp. 3115-3123, May 2017, doi: 10.1007/s11664-016-5196-8.

[2] M. F. Remeli, L. Tan, A. Date, B. Singh, and A. Akbarzadeh, "Simultaneous power generation and heat recovery using a heat pipe assisted thermoelectric generator system," Energy Convers. Manag., vol. 91, pp. 110-119, 2015, doi: 10.1016/j.enconman.2014.12.001.

[3] M. F. Remeli et al., "Experimental investigation of combined heat recovery and power generation using a heat pipe assisted thermoelectric generator system," Energy Convers. Manag., vol. 111, pp. 147-157, 2016, doi: 10.1016/j.enconman.2015.12.032.

[4] S. Tang et al., "Experimental investigation of a novel heat pipe thermoelectric generator for waste heat recovery and electricity generation," Int. J. Energy Res., vol. 44, no. 9, pp. 7450-7463, Jul. 2020, doi: 10.1002/ER.5465.

[5] N. Jaziri, A. Boughamoura, J. Müller, B. Mezghani, F. Tounsi, and M. Ismail, "A comprehensive review of Thermoelectric Generators: Technologies and common applications," Energy Reports, vol. 6, pp. 264287, Dec. 2020, doi: 10.1016/J.EGYR.2019.12.011.

[6] H. S. Lee, "Thermal Design: Heat Sinks, Thermoelectrics, Heat Pipes, Compact Heat Exchangers, and Solar Cells," Therm. Des. Heat Sink. Thermoelectr. Heat Pipes, Compact Heat Exch. Sol. Cells, Oct. 2010, doi: 10.1002/9780470949979.

[7] T. Y. Kim, J. Kwak, and B. Kim, "Energy harvesting performance of hexagonal shaped thermoelectric generator for passenger vehicle applications: An experimental approach," Energy Convers. Manag., vol. 160, pp. 14-21, Mar. 2018, doi: 10.1016/J.ENCONMAN.2018.01.032.

[8] H. Lee, J. Sharp, D. Stokes, M. Pearson, and S. Priya, "Modeling and analysis of the effect of thermal losses on thermoelectric generator performance using effective properties," Appl. Energy, vol. 211, pp. 987-996, Feb. 2018, doi: 10.1016/J.APENERGY.2017.11.096.

[9] A. Molki, "Simple Demonstration of the Seebeck Effect," Sci. Educ. Rev., 2010.

[10] T. Y. Kim, A. A. Negash, and G. Cho, "Experimental study of energy utilization effectiveness of thermoelectric generator on diesel engine,” Energy, vol. 128, pp. 531-539, Jun. 2017, doi: 10.1016/J.ENERGY.2017.04.060.

[11] R. Patowary and D. C. Baruah, "Thermoelectric conversion of waste heat from IC engine-driven vehicles: A review of its application, issues, and solutions," Int. J. Energy Res., vol. 42, no. 8, pp. 2595 2614, Jun. 2018, doi: 10.1002/er.4021.

[12] I. Temizer and C. Ilkiliç, "The performance and analysis of the thermoelectric generator system used in diesel engines," Renew. Sustain. Energy Rev., vol. 63, pp. 141-151, 2016, doi: 10.1016/j.rser.2016.04.068.

[13] C. Liu, X. Pan, X. Zheng, Y. Yan, and W. Li, "An experimental study of a novel prototype for two-stage 
thermoelectric generator from vehicle exhaust," J. Energy Inst., vol. 89, no. 2, pp. 271-281, 2016, doi: 10.1016/j.joei.2015.01.019.

[14] F. Yang, X. Yuan, and G. Lin, "Waste heat recovery using heat pipe heat exchanger for heating automobile using exhaust gas," Appl. Therm. Eng., vol. 23, no. 3, pp. 367-372, 2003, doi: 10.1016/S1359-4311(02)00190-4.

[15] Y. Y. Hsiao, W. C. Chang, and S. L. Chen, "A mathematic model of thermoelectric module with applications on waste heat recovery from automobile engine," Energy, vol. 35, no. 3, pp. 1447-1454, 2010, doi: 10.1016/j.energy.2009.11.030.

[16] S. C. Tzeng, T. M. Jeng, and Y. L. Lin, "Parametric study of heat-transfer design on the thermoelectric generator system," Int. Commun. Heat Mass Transf., vol. 52, pp. 97-105, 2014, doi: 10.1016/j.icheatmasstransfer.2014.01.021.

[17] S.-K. Kim, B.-C. Won, S.-H. Rhi, S.-H. Kim, J.-H. Yoo, and J.-C. Jang, "Thermoelectric Power Generation System for Future Hybrid Vehicles Using Hot Exhaust Gas," J. Electron. Mater., vol. 40, no. 5, pp. 778-783, May 2011, doi: 10.1007/s11664-011-1569-1.

[18] L. M. Goncalves, J. Martins, J. Antunes, R. Rocha, and F. P. Brito, "Heat-Pipe Assisted Thermoelectric Generators for Exhaust Gas Applications," Proc. Asme Int. Mech. Eng. Congr. Expo. - 2010, Vol 5, Pts a $B$, pp. 1387-1396, 2012, doi: 10.1115/IMECE2010-40926.

[19] S. Vijaya Kumar, A. K. Singh, A. Sabu, and M. P. Farhan, "Generation of Electricity by Using Exhaust from Bike,” Int. J. Innov. Res. Sci. Eng. Technol. (An ISO Certif. Organ., vol. 3297, no. 6, 2007, Accessed: May 30, 2018. [Online]. Available: www.ijirset.com.

[20] K. T. Zorbas, E. Hatzikraniotis, and K. M. Paraskevopoulos, "Power and Efficiency Calculation in Commercial TEG and Application in Wasted Heat Recovery in Automobile," 5th Eur. Conf. Thermoelectr., 2007.

[21] H. Yang, G. Shu, H. Tian, X. Ma, T. Chen, and P. Liu, "Optimization of thermoelectric generator (TEG) integrated with three-way catalytic converter (TWC) for harvesting engine's exhaust waste heat," Appl. Therm. Eng., vol. 144, pp. 628-638, Nov. 2018, doi: 10.1016/J.APPLTHERMALENG.2018.07.091.

[22] X. Liu, Y. D. Deng, S. Chen, W. S. Wang, Y. Xu, and C. Q. Su, “A case study on compatibility of automotive exhaust thermoelectric generation system, catalytic converter and muffler," Case Stud. Therm. Eng., 2014, doi: 10.1016/j.csite.2014.01.002.

[23] A. Montecucco, J. Siviter, and A. R. Knox, "The effect of temperature mismatch on thermoelectric generators electrically connected in series and parallel," Appl. Energy, vol. 123, pp. 47-54, Jun. 2014, doi: 10.1016/J.APENERGY.2014.02.030.

[24] B. Singh, A. Saoud, M. F. Remeli, L. C. Ding, A. Date, and A. Akbarzadeh, "Design and construction of a simple thermoelectric generator heat exchanger for power generation from salinity gradient solar pond," J. Teknol., vol. 76, no. 5, pp. 21-24, 2015, doi: 10.11113/jt.v76.5527. 